\title{
Article \\ Experimental Study on Breakthrough Separation for Hydrogen Recovery from Coke Oven Gas Using ZIF-8 Slurry
}

\author{
Wan Chen ${ }^{\dagger}$, Minglong Wang ${ }^{\dagger}$, Shaowu Yang, Zixuan Huang, Mingke Yang, Xiaowan Peng, Bei Liu * \\ and Guangjin Chen *
}

check for updates

Citation: Chen, W.; Wang, M.; Yang, S.; Huang, Z.; Yang, M.; Peng, X.; Liu, B.; Chen, G. Experimental Study on Breakthrough Separation for Hydrogen Recovery from Coke Oven Gas Using ZIF-8 Slurry. Energies 2022, 15, 1487. https://doi.org/10.3390/ en15041487

Academic Editors: Vladislav A. Sadykov and Prasad Kaparaju

Received: 25 December 2021 Accepted: 14 February 2022 Published: 17 February 2022

Publisher's Note: MDPI stays neutral with regard to jurisdictional claims in published maps and institutional affiliations.

Copyright: (C) 2022 by the authors. Licensee MDPI, Basel, Switzerland. This article is an open access article distributed under the terms and conditions of the Creative Commons Attribution (CC BY) license (https:// creativecommons.org/licenses/by/ $4.0 /)$.
State Key Laboratory of Heavy Oil Processing, China University of Petroleum, Beijing 102249, China; 2017313005@student.cup.edu.cn (W.C.); minglongwang929@163.com (M.W.); shaowuyang111@163.com (S.Y.); 2020310221@student.cup.edu.cn (Z.H.); 2018313045@student.cup.edu.cn (M.Y.); p_chemeng@163.com (X.P.)

* Correspondence: liub@cup.edu.cn (B.L.); gjchen@cup.edu.cn (G.C.)

+ These authors contributed equally to this work.

\begin{abstract}
A large amount of COG (coke oven gas) is produced from coking plants every year, which contains $55-60 \% \mathrm{H}_{2}$. In this work, the breakthrough separation of $\mathrm{H}_{2}$ from COG with ZIF8 /ethylene glycol-water slurry was studied. Following the investigation of the (ab-ad)sorption isotherms of the single component gas $\mathrm{CH}_{4}$ and $\mathrm{H}_{2}$, the main components of coke oven gas, in different slurries and their corresponding viscosities, and the influence of the operating conditions on the dynamic performance of $\mathrm{CH}_{4} / \mathrm{H}_{2}$ separation in slurry were studied in a bubble column. Low temperature, inlet flow rate, high pressure, and solid content can extend the breakthrough time, where the longest breakthrough time interval between $\mathrm{H}_{2}$ and $\mathrm{CH}_{4}$ can be as long as $70 \mathrm{~min}$, meaning the high purity of $\mathrm{H}_{2}$ product could be obtained easily. All the results of this work prove the feasibility of the slurry method to separate $\mathrm{CH}_{4} / \mathrm{H}_{2}$ mixture and provide a theoretical basis for practical industrial applications.
\end{abstract}

Keywords: coke oven gas; ZIF-8 slurry; gas separation; breakthrough experiment

\section{Introduction}

Coal plays a vital role in meeting global energy needs and is critical to infrastructure development. In China, the energy structure has traditionally been dominated by coal, accounting for about $60.4 \%$ of the total, and the output of raw coal was 3.52 billion tons in 2017. COG, the by-product of coking plants, is a kind of high calorific combustible gas with a heating value of $41.6 \mathrm{MJ} / \mathrm{kg}$, after recycling chemical products and purification to remove the complicated composition such as dust, tar, carbon, benzene, and naphthalene. Its main components are $\mathrm{H}_{2}(55-60 \%)$ and $\mathrm{CH}_{4}(23-27 \%)$, as well as a small amount of $\mathrm{CO}$, $\mathrm{CO}_{2}, \mathrm{~N}_{2}$, etc. [1]. A huge amount of $\mathrm{COG}$, about $7 \times 10^{10} \mathrm{~m}^{3}$, is produced every year, but unfortunately the majority was directly discharged into the atmosphere, causing serious environment pollution and a huge waste of energy resources. How to use it efficiently and reasonably is a significant issue related to environment protection, comprehensive resources utilization, energy conservation, and emission reduction. In recent years, the utilization of COG mainly includes direct combustion, power generation, synthetic chemical materials [2,3], direct reduction iron production, and hydrogen and syn-gas production [4], etc. In terms of the technology of producing high-purity hydrogen from COG, it has become focused by researchers for its maturation and significant economic benefits, especially compared with the hydrogen production by water electrolysis [5].

In the energy demand boom along with rapid industrialization and urban growth, hydrogen is proposed as an important energy source showing a great promise in the future, because of its clean, environmentally friendly, and high calorific value characteristics. Also, hydrogen is an important chemical raw material and plays an important role in the fields of ammonia industrial production, electronics industry, metal smelting, and petroleum 
refining. High-purity hydrogen can also be used in the field of fuel cells [6,7]. At present, hydrogen purification has received extensive attention, and various separation techniques have been developed, including cryogenic separation [8], pressure swing adsorption separation (PSA) [9], membrane separation [10,11], hydrate method [12,13], and other methods. The cryogenic separation process is complicated and considered to be highly energy intensive. So far, PSA is the most widely and relatively mature industrial separation method for $\mathrm{H}_{2}$ purification, due to its easy implementation, low energy requirement, low operating cost, and high product purity. For example, PSA is used in on-site coke plants in the steel industry to recover $\mathrm{H}_{2}$ from $\mathrm{COG}$ with different adsorbent materials such as alumina oxides or zeolites [14]. But meanwhile, before entering PSA, it is necessary for COG to remove tar, benzene-toluene-xylene (BTX), $\mathrm{H}_{2} \mathrm{~S}, \mathrm{NH}_{3}$, and light hydrocarbons, and other technologies are needed for whole exploitation of COG surplus. In addition, membrane separation technology [15] provides an attractive candidate to obtain hydrogen, especially in the research and development of some advanced materials, but the product purity of this process is limited to $95 \%$. As for hydrate separation [16], it is suitable for the separation of hydrogen-containing systems and has mild operating conditions with no need to remove light hydrocarbon, and other advantages, but it is still in a low stage of development. The development of a more efficient and friendly technology to recover $\mathrm{H}_{2}$ from $\mathrm{COG}$ is still required nowadays.

Zeolitic imidazolate frameworks (ZIFs) are zeolite-like frameworks materials that are synthesized by coordination of zinc atoms or cobalt atoms with organic ligands, with a large specific surface area, good hydrothermal stability, and long-time stability in organic solvents. ZIF-8 is made from the linking of zinc (II) cations and 2-methylimidazole anions, with a sodalite topology, whose pore cavity and theoretical pore aperture are $11.6 \AA$ and $3.4 \AA$, respectively [17]. It has been demonstrated to have the ability of separating small gas molecules from a gas mixture, such as the separation of $\mathrm{H}_{2}$ from $\mathrm{CH}_{4} / \mathrm{H}_{2}$, and the ideal selectivity is 11-14 [18-20]. Liu et al. [21] proposed a ZIF-8/glycol-water slurry absorptionadsorption hybrid method to separate the gas mixture, where ZIF-8 can be suspended in water and maintain its adsorption performance because of its hydrophobicity and the similar density to water. By experiments, the solubility and separation performance of the slurry for carbon dioxide [22,23], low-boiling hydrocarbon [21], and their mixtures [24,25] were studied, and a continuous (ab-ad)sorption-desorption process was proposed with its mathematical model also developed [26]. Furthermore, the (ab-ad)sorption-desorption process was successfully run in a pilot-scale plant with promising results $[27,28]$. Compared with cryogenic separation, the operating conditions of the slurry method are more flexible and gentle. Compared with PSA, the slurry separation can be operated in an absorption column continuously. In addition, its energy consumption can be reduced with heat integration technology. Recently, Li et al. developed a green approach for large-scale synthesis of ZIFs, which greatly reduces the cost of ZIFs and is beneficial for the industrial application of ZIFs [29].

The breakthrough experiment can be used to evaluate the sorption and separation ability of the sorption medium to the gas mixtures. The principle is to use the difference in the sorption rate of the sorption medium to ab/adsorb the components of the mixture to separate the mixture. Chiau Junior et al. selected the best adsorbent for $\mathrm{CH}_{4} / \mathrm{H}_{2}$ separation among various MOFs materials and conducted breakthrough experiments. Their results showed that the UMODEH08 or UMOBEF04 are superior candidate adsorbents of the practical adsorption separation for $\mathrm{H}_{2} / \mathrm{CH}_{4}$ mixture [30]. Liu et al. reported a method for breakthrough separation of $\mathrm{CO}_{2}$ from various gas mixtures using ZIF-8/2-methylimidazoleglycol slurry and found the slurry can efficiently remove $\mathrm{CO}_{2}$ from gas mixtures at normal pressures/temperatures [22]. Pan et al. used ZIF-67/2-methylimidazole-glycol slurry for breakthrough separation of a $\mathrm{CO}_{2} / \mathrm{H}_{2}, \mathrm{CO}_{2} / \mathrm{N}_{2}$, and $\mathrm{CO}_{2} / \mathrm{CH}_{4}$ mixture and also achieved good separation results [31].

In this work, the ZIF-8 slurry was adopted to separate COG. A series of intermittent separation of $\mathrm{CH}_{4} / \mathrm{H}_{2}$ mixture, which are used to simulate $\mathrm{COG}$ as $\mathrm{CH}_{4}$ and $\mathrm{H}_{2}$ are its 
main components, were performed by bubbling the gas mixtures through a bubble column with ZIF-8 slurry. The experiment results demonstrated that there is significant difference between the breakthrough time of hydrogen and that of methane and this kind of difference could be enhanced by decreasing the operation temperature, increasing the operation pressure or increasing the solid fraction of the slurry. This work indicates that the ZIF-8 slurry is very suitable for recovering hydrogen from COG and high purity of $\mathrm{H}_{2}$ could be obtained easily.

\section{Materials and Methods}

\subsection{Materials}

In this work, ZIF-8 and deionized water were both made by ourselves [29], and ethylene glycol (analytical grade) was purchased from Sigma-Aldrich Corporation (Shanghai, China). Hydrogen (99.99\%), methane (99.99\%), and their gas mixtures were purchased from Beijing AP Beifen Gases Industry Company (Beijing, China).

\subsection{Experimental Apparatus}

The apparatus that was used in single component gas (ab-ad)sorption and the viscosity measurements have been mentioned in our previous works [21-23,32]. The procedure of determining the solubility of gas in phase equilibrium (calculated by the law of conservation of mass and material balance) was also described in these literatures. The bubble column that was used for the $\mathrm{CH}_{4} / \mathrm{H}_{2}$ mixture breakthrough device is shown in Figure 1 . It is a batch absorption-adsorption separation device with a volume of $700 \mathrm{~mL}$. The device that was used to measure viscosity, the NDJ-8S, is shown in Figure 2.

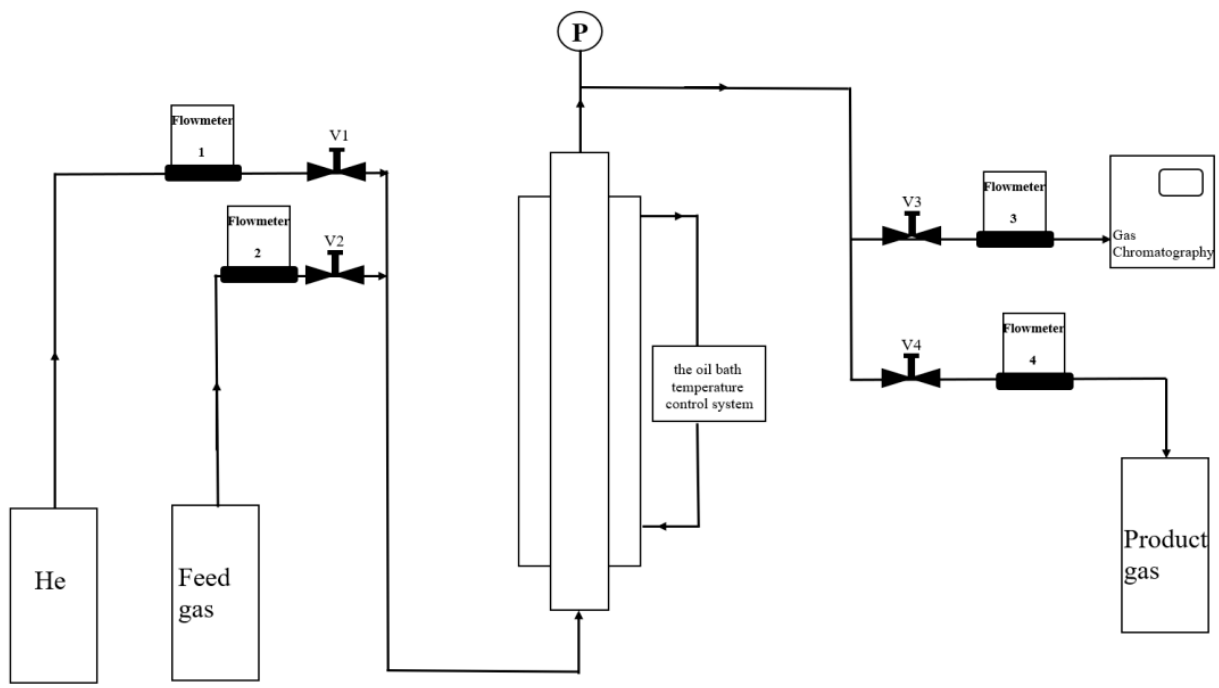

Figure 1. Schematic diagram of the kinetic experimental device for the separation experiments.

\subsection{Experimental Procedures}

In the preparation stage before the experiment, the inlet and outlet valves of the bubble column were closed, and a certain amount of deionized water together with helium was loaded into the bubble column. The constant state of the temperature and pressure in the bubble column for $2 \mathrm{~h}$ implied the good air tightness of the device, meaning the experiment was ready to get started. To begin with, the well washed bubble column was loaded with the prepared $600 \mathrm{~mL}$ ZIF-8 slurry and the oil bath temperature control system was turned on and set with the experimental value to maintain the temperature of the bubble column. Then, the helium inlet valve was opened, meanwhile the back pressure valve on the outlet pipe was adjusted to make the pressure in the bubble column reach the experiment value. After the temperature and pressure became constant, the helium valve was shut off while the feed gas valve was opened, and the flow of feed gas inflation was adjusted with the 
flowmeter. Meanwhile, the outlet flow corresponding to different moments was recorded and the outlet gas was collected for composition analysis with a chromatograph.

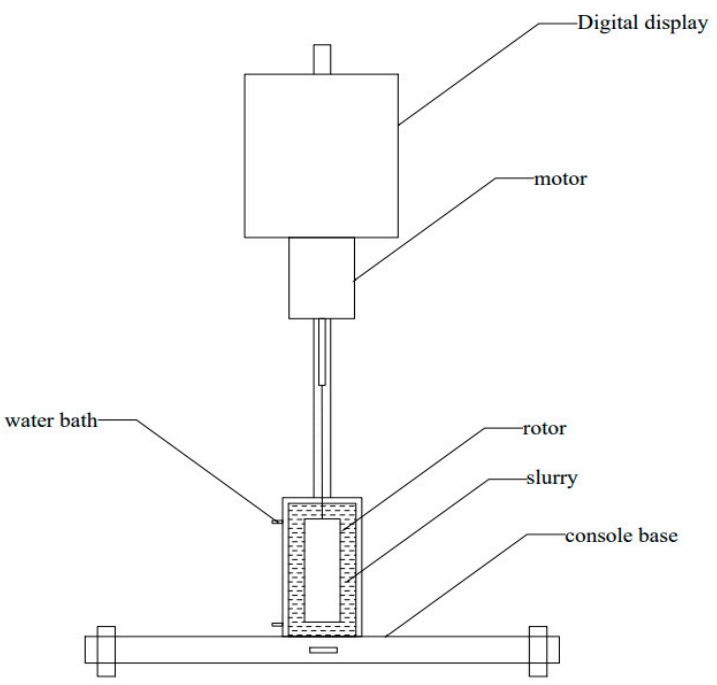

Figure 2. Diagram of a controlled temperature experimental apparatus for the slurry viscosity measurement.

In the process of viscosity measurements, firstly, the viscosity measurement device was connected to the water bath temperature control system. After the set temperature was constant, the prepared slurry was slowly poured into the equipment and the motor speed was adjusted to $60 \mathrm{r} / \mathrm{min}$. When the data on the display had stabilized for a period of time, the viscosity of the slurry under this condition was recorded.

\subsection{Data Processing}

In the breakthrough experiment, the instantaneous recovery rate of $\mathrm{CH}_{4}$ in the slurry, $R_{\mathrm{CH} 4}$, was calculated as below:

$$
R_{\mathrm{CH}_{4}}=1-\frac{v_{\text {out }} \times y_{\text {out }-\mathrm{CH}_{4}}}{v_{\text {in }} \times y_{\text {in }-\mathrm{CH}_{4}}} \times 100 \%
$$

where $v_{\text {in }}$ and $v_{\text {out }}$ are the flow rates of the inlet and outlet gas, respectively. $y_{\text {in-CH4 }}$ and $y_{\text {out-CH4 }}$ are the mole concentrations of $\mathrm{CH}_{4}$ at the entrance and exit, respectively.

The instantaneous recovery rate of $\mathrm{H}_{2}$ in the outlet, $R_{\mathrm{H} 2}$, was calculated as below:

$$
R_{\mathrm{H}_{2}}=\frac{v_{\text {out }} \times y_{\text {out }-\mathrm{H}_{2}}}{v_{\text {in }} \times y_{\text {in }-\mathrm{H}_{2}}} \times 100 \%
$$

where $y_{\mathrm{in}-\mathrm{H} 2}$ and $y_{\text {out }-\mathrm{H} 2}$ are the mole concentrations of $\mathrm{H}_{2}$ at the entrance and exit, respectively.

\section{Results and Discussion}

\subsection{Gas-Slurry Phase Equilibrium Experiments}

ZIF-8 slurry is composed of solid material ZIF-8, ethylene glycol, and water, wherein the ratio of ethylene glycol to water is $1 / 4$ as the optimal value [19]. In our previous work, we measured the uptake of $\mathrm{CH}_{4}$ and $\mathrm{H}_{2}$ in $20 \mathrm{wt} \%$ ethanol aqueous solution at $273.15 \mathrm{~K}$. The results show that the solution has a certain separation effect on $\mathrm{CH}_{4} / \mathrm{H}_{2}$. By adding ZIF-8 to the solution and measuring the uptake of gases in ZIF-8/ethanol slurry, we found the uptake of $\mathrm{CH}_{4}$ in the ZIF-8 slurry is about ten times that in glycol aqueous solution. The addition of ZIF-8 slightly increases the $\mathrm{H}_{2}$ uptake, while sharply increasing the sorption amount of $\mathrm{CH}_{4}$, which greatly improved the separation factor of $\mathrm{CH}_{4}$ over $\mathrm{H}_{2}$ [33]. The addition of ethylene glycol can better disperse ZIF-8 in water and reduce the foaming 
degree of the slurry. Meanwhile, it can remove the osmotic pressure of excessive ethylene glycol, which can influence the solubility of the small molecule gas. Therefore, the liquid solvent of the ZIF-8 slurry in this article is all at the above ratio. The content of ZIF-8 in slurry contributes to the increase of the viscosity of the slurry, which is an important physical property in industrial applications and has a great influence on the mass transfer rate and flow resistance. Viscosity will affect the mass transfer rate. When the viscosity increases, the fluidity of the slurry becomes poor, and the mass transfer rate between the gas and the slurry will decrease accordingly. Conversely, when the viscosity decreases, the mass transfer rate between the gas and the slurry increases, which is beneficial for the sorption of the gas by the slurry. From Table 1, it can be seen that when the solid content is constant, the viscosity of the slurry decreases with increasing temperature, which can be attributed to a higher temperature that can promote the fluidity and increase the kinetic energy of the slurry. Table 1 also shows that the viscosity of the slurry increases with the increase of the solid content at the same temperature. For example, when the solid contents are 20, 25, and $30 \mathrm{wt} \%$, respectively, the viscosities at $273.15 \mathrm{~K}$ are $12.8,14.6$, and $26.9 \mathrm{mPa} \cdot \mathrm{s}$, correspondingly.

Table 1. Comparison of the viscosities of the slurries with different solid and the same solvent (ethylene glycol $20 \mathrm{wt} \%$ + water $80 \mathrm{wt} \%$ ) contents at different temperatures and normal pressure.

\begin{tabular}{|c|c|c|c|c|}
\hline \multicolumn{2}{|c|}{ Slurry Composition } & \multicolumn{3}{|c|}{ Viscosity, (mPa.s) } \\
\hline Solid Content $m_{\mathrm{F}}(\mathbf{w t} \%)$ & Solvent Content, $(w t \%)$ & $273.15 \mathrm{~K}$ & $278.15 \mathrm{~K}$ & $283.15 \mathrm{~K}$ \\
\hline 20 & 80 & 12.8 & 11.8 & 10.3 \\
\hline 25 & 75 & 14.6 & 13.1 & 11.4 \\
\hline 30 & 70 & 26.9 & 24.8 & 21.6 \\
\hline
\end{tabular}

The sorption isotherms of $\mathrm{CH}_{4}$ and $\mathrm{H}_{2}$ in the slurry (ZIF-8 $20 \mathrm{wt} \%+$ ethylene glycol $16 \mathrm{wt} \%$ + water $64 \mathrm{wt} \%$ ) at different temperatures were measured and the results are given in Figure 3. As ordinary absorption processes, in the ZIF-8 slurry lower (ab-ad)sorption temperature and higher (ab-ad)sorption pressure increase the uptake of gas. By comparing the sorption isotherms of $\mathrm{CH}_{4}$ and $\mathrm{H}_{2}$ in the slurry at $273.15 \mathrm{~K}$, it is clear that under the same conditions, the sorption capacity of $\mathrm{CH}_{4}$ is much higher than that of $\mathrm{H}_{2}$, which provides the possibility of separation of the $\mathrm{CH}_{4} / \mathrm{H}_{2}$ mixture. The pressure of the water system to form methane hydrate and hydrogen hydrate are $2.534 \mathrm{MPa}$ and $400 \mathrm{MPa}$ at $273.15 \mathrm{~K}$. The presence of ethylene glycol inhibits the formation of methane hydrate and hydrogen hydrate. Therefore, the hydrate formation pressure in the slurry will be higher and hydrate will not be formed under the experimental conditions of this work.

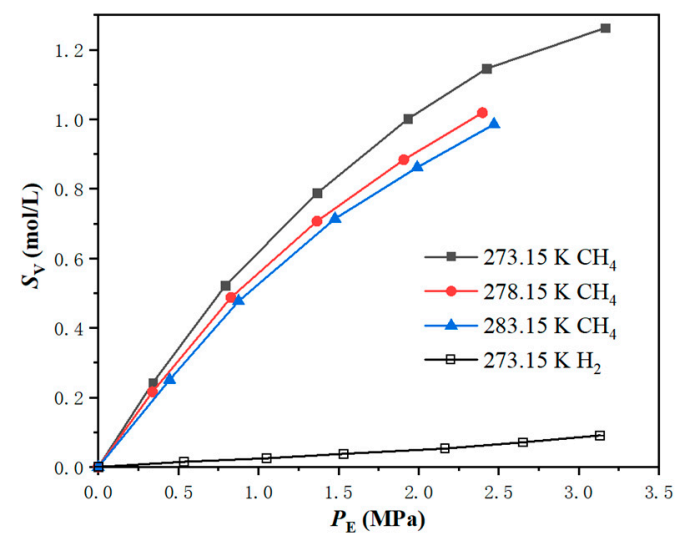

Figure 3. Solubility of $\mathrm{CH}_{4}$ and $\mathrm{H}_{2}$ in the slurry (ZIF-8 $20 \mathrm{wt} \%+$ ethylene glycol $16 \mathrm{wt} \%+$ water $64 \mathrm{wt} \%$ ) at different temperatures. 


\subsection{Breakthrough Experiments}

The ultimate aim of separating the gas mixture by an absorption-adsorption hybrid method is to realize the industrial application of this separation technology. The phase equilibrium separation experiment has shown that a ZIF-8/water-ethylene glycol slurry can capture $\mathrm{H}_{2}$ from coke oven gas, but there are still a number of uncertain factors in the gas continuous separation in a practical industrial absorption column, such as the fluidity of the slurry in its moving and mass transfer processes, etc. To simulate the separation capacity of ZIF-8 slurry in the practical industrial process of hydrogen recovery from coke oven gas, and because of the foundation status of the bubble column absorption separation in all kinds of separation processes, in this work a bubble column dynamic evaluation device was used to study the sorption capacity of a ZIF-8 slurry in a $\mathrm{CH}_{4} / \mathrm{H}_{2}$ mixture. The feasibility of the hydrogen recovery process with the ZIF-8 slurry in the practical industrial absorption column can then get verified. The influences of the slurry solid content, temperature, operating pressure, and inlet flow rate on the breakthrough experiment were systematically studied. The changes of the $\mathrm{CH}_{4}$ and $\mathrm{H}_{2}$ concentration in the outlet gas with time are plotted in Figure 4 and the breakthrough time of $\mathrm{CH}_{4}$ and $\mathrm{H}_{2}$ and their difference are summarized in Table 2.

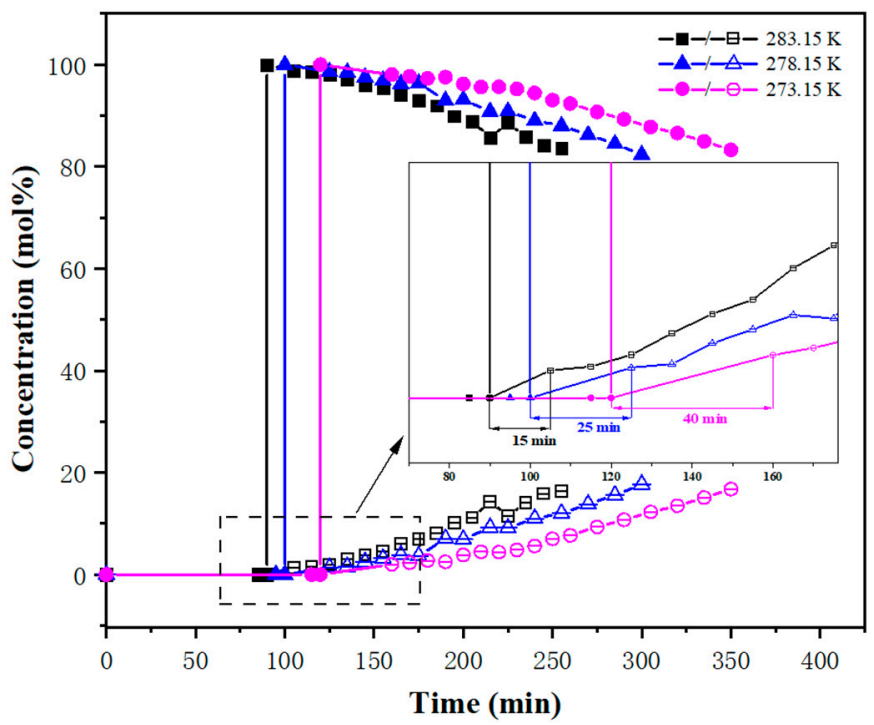

Figure 4. Breakthrough experimental results of $\mathrm{CH}_{4} / \mathrm{H}_{2}(34.22 / 65.78 \mathrm{~mol} \%)$ mixture separation in a slurry of ZIF-8 $20 \mathrm{wt} \%$ + ethylene glycol $16 \mathrm{wt} \%$ + water $64 \mathrm{wt} \%$ at the inlet gas flow rate of $27.72 \mathrm{~mL} / \mathrm{min}$, as well as conditions: $2.0 \mathrm{MPa}$, different temperatures of $283.15 \mathrm{~K}, 278.15 \mathrm{~K}$, and $273.15 \mathrm{~K}$. (The solid curve in the figure is $\mathrm{H}_{2}$ and the hollow curve is $\mathrm{CH}_{4}$ ).

Table 2. Comparison of the breakthrough time of $\mathrm{CH}_{4}$ and $\mathrm{H}_{2}$ and their difference under different experimental conditions.

\begin{tabular}{|c|c|c|c|c|c|c|}
\hline$m_{\mathrm{F}},(\mathrm{wt} \%)$ & $T,(\mathrm{~K})$ & $P,(\mathrm{MPa})$ & $v_{\text {in }}(\mathrm{mL} / \mathrm{min})$ & $t_{\mathrm{H} 2},(\min )$ & $t_{\mathrm{CH} 4},(\mathrm{~min})$ & $\Delta t,(\min )$ \\
\hline \multirow{3}{*}{20} & 273.15 & & \multirow{3}{*}{27.72} & 120 & 160 & 40 \\
\hline & 278.15 & 2.0 & & 100 & 125 & 25 \\
\hline & 283.15 & & & 90 & 105 & 15 \\
\hline \multirow[b]{2}{*}{20} & \multirow{2}{*}{273.15} & 1.5 & \multirow[b]{2}{*}{27.72} & 100 & 130 & 30 \\
\hline & & 2.5 & & 160 & 225 & 65 \\
\hline 25 & \multirow{2}{*}{273.15} & \multirow{2}{*}{2.0} & \multirow{2}{*}{27.72} & 130 & 180 & 50 \\
\hline 30 & & & & 150 & 220 & 70 \\
\hline \multirow[b]{2}{*}{20} & \multirow{2}{*}{273.15} & \multirow[b]{2}{*}{2.0} & 36.96 & 90 & 115 & 25 \\
\hline & & & 46.20 & 50 & 60 & 10 \\
\hline
\end{tabular}


Figure 4 shows the (ab-ad)sorption breakthrough curves of $\mathrm{CH}_{4} / \mathrm{H}_{2}(34.22 / 65.78 \mathrm{~mol} \%)$ mixture in a slurry (ZIF-8 $20 \mathrm{wt} \%$ + ethylene glycol $16 \mathrm{wt} \%$ + water $64 \mathrm{wt} \%$ ) at $2.0 \mathrm{MPa}$ and different temperatures. Taking $273.15 \mathrm{~K}$ as an example, within $120 \mathrm{~min}, \mathrm{H}_{2}$ and $\mathrm{CH}_{4}$ were completely (ab-ad)sorbed by the slurry and no gas was detected at the outlet. Over that time, $\mathrm{H}_{2}$ and $\mathrm{CH}_{4}$ were detected at $120 \mathrm{~min}$ and $160 \mathrm{~min}$, respectively, which illustrates that the competitive sorption is more conducive to $\mathrm{CH}_{4}$, making the slurry's solubility of $\mathrm{CH}_{4}$ higher than $\mathrm{H}_{2}$, so that the $\mathrm{CH}_{4} / \mathrm{H}_{2}$ mixture can be effectively separated. This result is consistent with the above-mentioned (ab-ad)sorption isotherm of a single component gas. It is particularly worth noting that the outlet gas product is pure $\mathrm{H}_{2}$ within 120-160 min, which has significant economic benefits. Comparing the breakthrough curves at different temperatures, one can know that the breakthrough times of $\mathrm{H}_{2}$ and $\mathrm{CH}_{4}$, as well as their difference, increase with decreasing temperature, indicating that low temperature can promote the separation of the $\mathrm{CH}_{4} / \mathrm{H}_{2}$ mixture. In terms of the breakthrough time differences of $\mathrm{H}_{2}$ and $\mathrm{CH}_{4}$ at $283.15 \mathrm{~K}, 278.15 \mathrm{~K}$, and $273.15 \mathrm{~K}$, the values were $15 \mathrm{~min}$, $25 \mathrm{~min}$, and $40 \mathrm{~min}$, respectively. It also can be seen that when temperature is reduced by $10 \mathrm{~K}$, the time to obtain pure $\mathrm{H}_{2}$ increases by 1.67 times. A low temperature will increase the viscosity of the slurry, which is not conducive to the mass transfer between the gas and the slurry. On the other hand, the solubility of the slurry to $\mathrm{CH}_{4}$ becomes higher when decreasing the temperature, as shown in Figure 3, which reinforces the driving force between the gas phase and the slurry phase and then promotes the mass transfer. The result of the combined effect of these two aspects is the increase of permeation time, indicating that the latter has a greater impact on the mass transfer.

Figure 5 shows the effect of the operating pressures on the breakthrough curve. It can be seen that the higher the operating pressure is, the longer it takes for the gas to break through the slurry bed. When the operating pressures are $1.5,2.0$, and $2.5 \mathrm{MPa}$, the breakthrough times for $\mathrm{H}_{2}$ are 100, 120, and $160 \mathrm{~min}$, and for $\mathrm{CH}_{4}$ are 130, 160, and $225 \mathrm{~min}$, respectively. Under high pressure, the gas (ab-ad)sorption rate is accelerated, since pressure is the driving force for mass transfer between the gas phase and the slurry. In addition, the solubility of the gas increases at the same inlet flow rate with increasing pressure, and at pressures below 3.0 MPa, methane and hydrogen do not form hydrates, as shown in Figure 3. As such, under a higher pressure, the amount of gas that is processed by the slurry becomes larger. Influenced by the above two factors, the breakthrough time extended with increasing pressure.

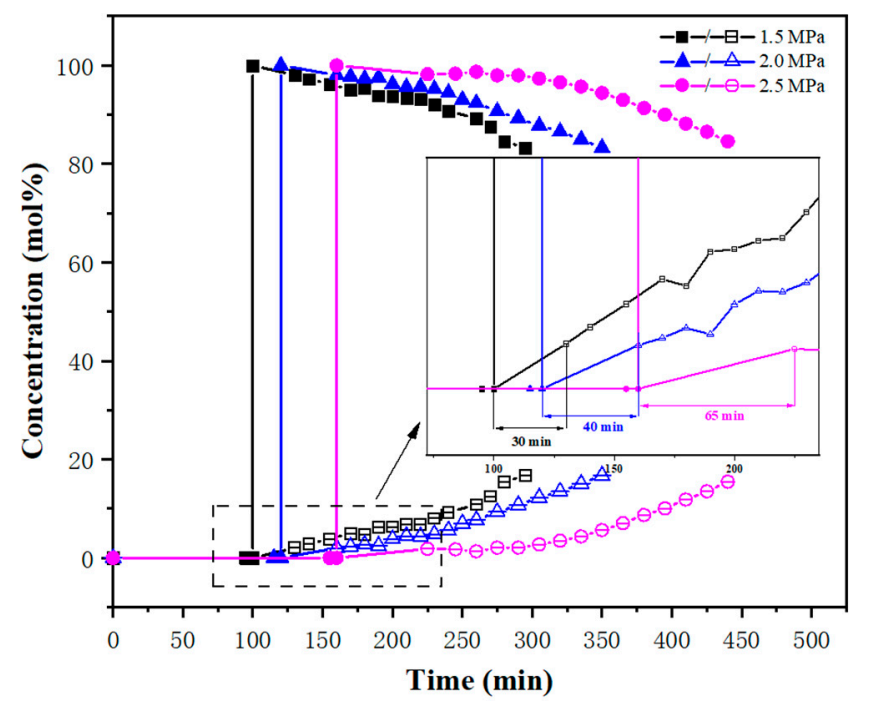

Figure 5. Breakthrough experimental results of a $\mathrm{CH}_{4} / \mathrm{H}_{2}(34.22 / 65.78 \mathrm{~mol} \%)$ mixture separation in a slurry of ZIF-8 $20 \mathrm{wt} \%$ + ethylene glycol $16 \mathrm{wt} \%$ + water $64 \mathrm{wt} \%$ at the inlet gas flow rate of $27.72 \mathrm{~mL} / \mathrm{min}$, as well as conditions: $273.15 \mathrm{~K}$, different pressures of $1.5 \mathrm{MPa}$, 2.0 MPa, and 2.5 $\mathrm{MPa}$. (The solid curve in the figure is $\mathrm{H}_{2}$ and the hollow curve is $\mathrm{CH}_{4}$ ). 
By reasonably increasing the solid content of the slurry, the separation performance can be improved; however, not only the cost but also the viscosity of the slurry will increase. To study the effect of solid content on the mass transfer rate, slurries with different ZIF-8 contents of 20,25 , and $30 \mathrm{wt} \%$ were used to conduct the breakthrough experiment at $273.15 \mathrm{~K}, 2.0 \mathrm{MPa}$, and the inlet flow rate of $27.72 \mathrm{~mL} / \mathrm{min}$, and the results are shown in Figure 6. According to Figure 6, with increasing the solid content, the start breakthrough times of $\mathrm{H}_{2}$ and $\mathrm{CH}_{4}$ increase, and so does the breakthrough time interval between the two gases, indicating a promotion in the mass transfer between the gas phase and the slurry. This is inconsistent with our expectation that the increase of the solid content increases the viscosity of the slurry, which is not conducive to mass transfer. The reasons for this contradiction were analyzed as below: on one hand, the range of the viscosity of the slurry that was studied in this work does not have a decisive effect on the mass transfer rate. On the other hand, the increase of the solid content can improve the stability of the slurry and increase the probability of gas-solid contact, so that mass transfer is promoted. According to Table 3, when the solid content was 20, 25, and $30 \mathrm{wt} \%$, the breakthrough times of $\mathrm{CH}_{4}$ were 160, 180, and $220 \mathrm{~min}$, respectively, indicating that with increasing rates of $25 \%$ and $50 \%$ in solid content, the increasing rates of $\mathrm{CH}_{4}$ breakthrough time are $12.5 \%$ and $37.5 \%$, respectively, all compared with the first set of data. The greater increasing range of breakthrough times than that of the solid content indicates that a further increase of the solid content can be expected for a larger saturated solubility of $\mathrm{CH}_{4}$, the better mass transfer and the longer time to obtain pure $\mathrm{H}_{2}$. However, considering the cost of ZIF- 8 and the content of it on the viscosity of the slurry, its optimal content needs to be evaluated.

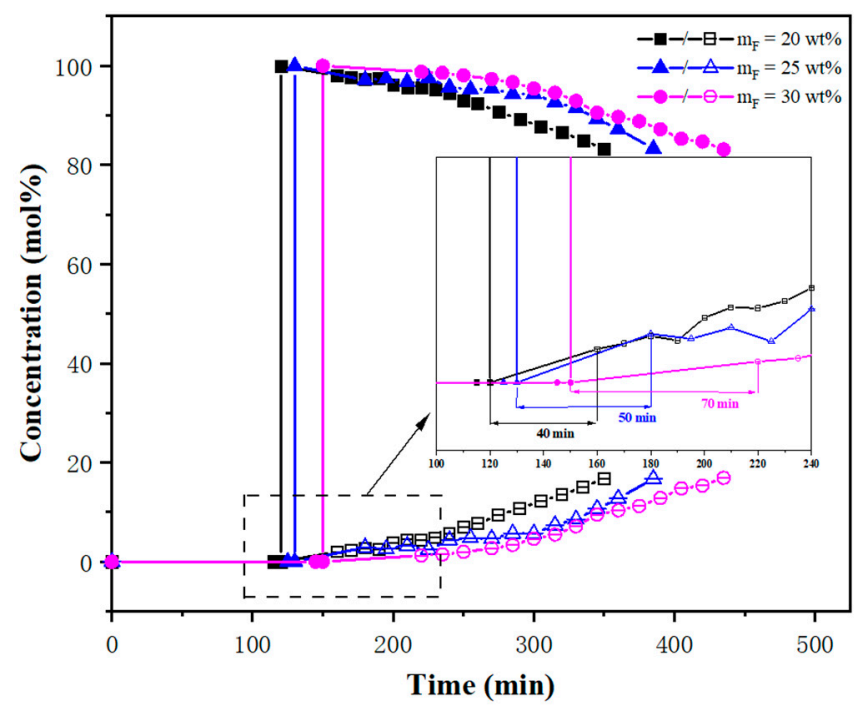

Figure 6. Breakthrough experimental results of the $\mathrm{CH}_{4} / \mathrm{H}_{2}(34.22 / 65.78 \mathrm{~mol} \%)$ mixture in the slurry with different solid contents of $20 \mathrm{wt} \%, 25 \mathrm{wt} \%$, and $30 \mathrm{wt} \%$, at $273.15 \mathrm{~K}, 2.00 \mathrm{MPa}$, and an inlet gas flow rate of $27.72 \mathrm{~mL} / \mathrm{min}$. (The solid curve in the figure is $\mathrm{H}_{2}$ and the hollow curve is $\mathrm{CH}_{4}$ ).

The flow rate is a key parameter for continuous and stable operation, which is related to the mass transfer rate of the gas and separation medium and is an economic indicator for evaluating the separation process. A high flow rate means a large amount of handling capacity, but at the same time a compromise separation effect. The influence of flow rate on the breakthrough curve reflects the diffusion of the gas molecules from the gas phase to the slurry phase. Figure 6 shows that with the increase of the flow rate, the breakthrough points of $\mathrm{H}_{2}$ and $\mathrm{CH}_{4}$ kept advancing, indicating that a smaller flow rate with a longer residence time is favorable for the (ab-ad)sorption of the gas mixture. When the flow rate increases, the amount of gas molecules that are (ab-ad)sorbed by the slurry reduces in the corresponding short residence time due to the existence of mass transfer resistance, thereby the gas breaks through the slurry bed and reaches the outlet. As shown in Figure 7 , 
after the breakthrough with a higher feed flow rate, the concentration of $\mathrm{CH}_{4}$ in the outlet gas increases faster and the shape of the breakthrough curve of $\mathrm{CH}_{4}$ becomes steeper. In general, the effect of mass transfer resistance on the separation performance cannot be ignored under the experimental conditions.

Table 3. Results of the breakthrough experiment for the $\mathrm{CH}_{4} / \mathrm{H}_{2}(34.22 / 65.78 \mathrm{~mol} \%)$ mixture separation in a slurry of ZIF-8 $30 \mathrm{wt} \%$ + ethylene glycol $14 \mathrm{wt} \%$ + water $56 \mathrm{wt} \%$ at $273.15 \mathrm{~K}, 2.0 \mathrm{MPa}$, with an inlet flow rate of $27.72 \mathrm{~mL} / \mathrm{min}$.

\begin{tabular}{|c|c|c|c|c|}
\hline Time (min) & $y_{\text {out-H}} / y_{\text {out-CH}},(\mathrm{mol} \%)$ & $v_{\text {out }},\left(\mathrm{mL} \cdot \mathrm{min}^{-1}\right)$ & $R_{\mathrm{H} 2},(\%)$ & $R_{\mathrm{CH} 4},(\%)$ \\
\hline 0 & $0 / 0$ & 0 & 0 & 0 \\
\hline 120 & $100 / 0$ & 6.38 & 35.57 & 100 \\
\hline 160 & $98.03 / 1.97$ & 12.41 & 67.82 & 97.42 \\
\hline 170 & $97.70 / 2.30$ & 13.85 & 75.43 & 96.64 \\
\hline 180 & $97.26 / 2.74$ & 14.51 & 78.67 & 95.81 \\
\hline 200 & $96.19 / 3.81$ & 16.08 & 86.23 & 93.54 \\
\hline 220 & $95.63 / 4.38$ & 17.05 & 90.88 & 92.13 \\
\hline 230 & $95.21 / 4.79$ & 17.69 & 93.89 & 91.07 \\
\hline 240 & $94.43 / 5.57$ & 18.14 & 95.49 & 89.35 \\
\hline 250 & $93.03 / 6.97$ & 18.53 & 96.10 & 86.38 \\
\hline 260 & $92.34 / 7.66$ & 18.87 & 97.14 & 84.76 \\
\hline 275 & $90.67 / 9.33$ & 19.02 & 96.14 & 81.29 \\
\hline 290 & $89.27 / 10.73$ & 19.46 & 96.84 & 77.99 \\
\hline 305 & $87.77 / 12.23$ & 19.68 & 96.29 & 74.63 \\
\hline
\end{tabular}

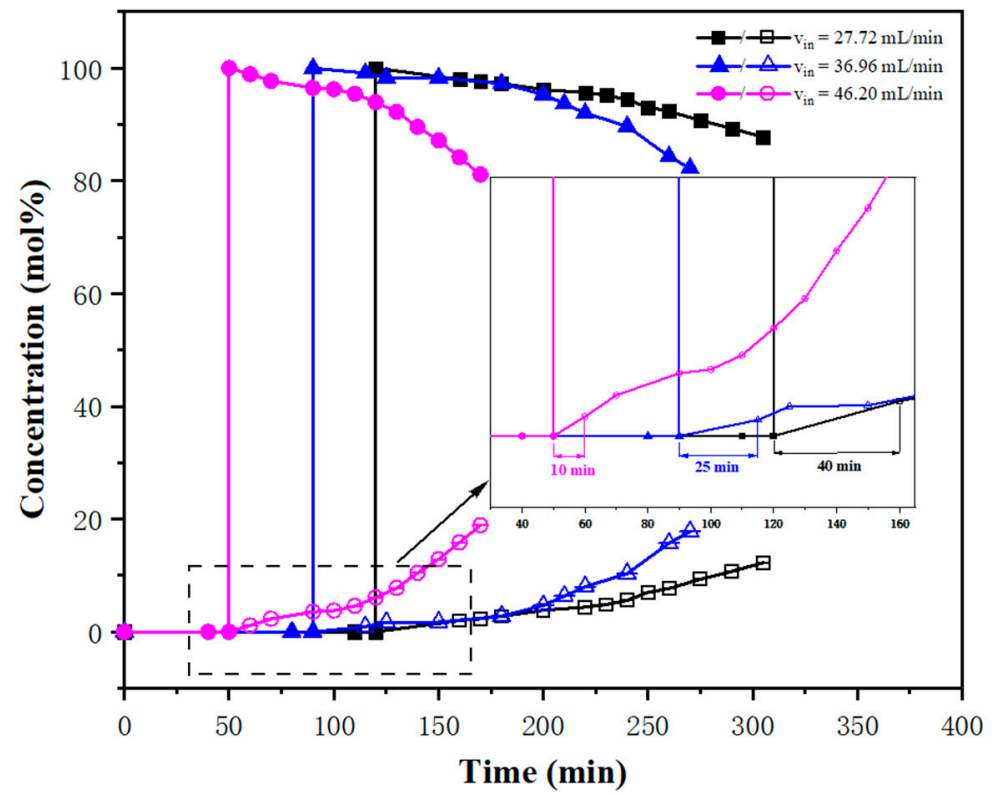

Figure 7. Breakthrough experimental results of the $\mathrm{CH}_{4} / \mathrm{H}_{2}(34.22 / 65.78 \mathrm{~mol} \%)$ mixture separation in a slurry of ZIF-8 $20 \mathrm{wt} \%$ + ethylene glycol $16 \mathrm{wt} \%$ + water $64 \mathrm{wt} \%$, at $273.15 \mathrm{~K}, 2.0 \mathrm{MPa}$, and different inlet flow rates of $27.72 \mathrm{~mL} / \mathrm{min}, 36.96 \mathrm{~mL} / \mathrm{min}$, and $46.20 \mathrm{~mL} / \mathrm{min}$. (The solid curve in the figure is $\mathrm{H}_{2}$ and the hollow curve is $\mathrm{CH}_{4}$ ).

The flow rate and the composition of outlet gas at different inlet flow rates were shown in Tables 3-5. In addition, the instantaneous recovery rate of $\mathrm{H}_{2}$ in the outlet $\left(\mathrm{R}_{\mathrm{H} 2}\right)$ and $\mathrm{CH}_{4}$ in the slurry $\left(\mathrm{R}_{\mathrm{CH}}\right)$ were calculated and given. According to the tables, the flow rate and $\mathrm{CH}_{4}$ concentration of the outlet gas gradually increased over time, due to the limited (ab-ad)sorption capacity of the slurry system for $\mathrm{H}_{2}$ and $\mathrm{CH}_{4} \cdot \mathrm{R}_{\mathrm{H} 2}$ firstly increases with the separation time advancing and the values of $\mathrm{R}_{\mathrm{H} 2}$ are over $100 \%$ when the inlet flow rate is $36.96 \mathrm{~mL} / \mathrm{min}$ (after $200 \mathrm{~min}$ ) or $46.20 \mathrm{~mL} / \mathrm{min}$ (after $100 \mathrm{~min}$ ), indicating that $\mathrm{H}_{2}$ 
is no longer (ab-ad)sorbed but becomes desorbed from the slurry. That is because the concentration of $\mathrm{CH}_{4}$ in the slurry continues to increase, causing the increase of the partial pressure of $\mathrm{CH}_{4}$, in other words, the decrease of $\mathrm{H}_{2}$ partial pressure. When the partial pressure of $\mathrm{H}_{2}$ decreases to a certain degree, with the $\mathrm{CH}_{4}$ stripping, the (ab-ad)sorbed $\mathrm{H}_{2}$ in the slurry will escape, making the $\mathrm{R}_{\mathrm{H} 2}$ over $100 \%$. With time going on, the $\mathrm{CH}_{4}(\mathrm{ab}-$ ad)sorption capacity of the slurry gradually becomes saturated, and the $\mathrm{CH}_{4}$ concentration in the outlet gas increases, causing the decrease of $\mathrm{R}_{\mathrm{H} 2}$, and tending to $100 \%$ eventually. By comparing Tables $3-5$, it can be found that when the inlet flow rate increases, the time for $\mathrm{R}_{\mathrm{H} 2}$ to exceed $100 \%$ advances, and the corresponding $\mathrm{CH}_{4}$ concentration in the outlet gas reduces. This indicates that the slurry (ab-ad)sorbs $\mathrm{CH}_{4}$ preferentially to $\mathrm{H}_{2}$ and the (ab-ad)sorption rate for $\mathrm{CH}_{4}$ is faster. In addition, from Tables 3-5 we can see that the values of $\mathrm{R}_{\mathrm{CH} 4}$ are still more than $50 \%$ at $270 \mathrm{~min}, 36.96 \mathrm{~mL} / \mathrm{min}$ and $170 \mathrm{~min}, 46.20 \mathrm{~mL} / \mathrm{min}$, showing a certain degree of $\mathrm{CH}_{4}(\mathrm{ab}-\mathrm{ad})$ sorption capacity of the slurry system.

Table 4. The results of the breakthrough experiment for the $\mathrm{CH}_{4} / \mathrm{H}_{2}(34.22 / 65.78 \mathrm{~mol} \%)$ mixture separation in a slurry of ZIF-8 $30 \mathrm{wt} \%$ + ethylene glycol $14 \mathrm{wt} \%$ + water $56 \mathrm{wt} \%$ at $273.15 \mathrm{~K}, 2.0 \mathrm{MPa}$, with an inlet flow rate of $36.96 \mathrm{~mL} / \mathrm{min}$.

\begin{tabular}{|c|c|c|c|c|}
\hline Time (min) & $y_{\text {out-H}} / y_{\text {out }-\mathrm{CH} 4},(\mathrm{~mol} \%)$ & $v_{\text {out }},\left(\mathrm{mL} \cdot \mathrm{min}^{-1}\right)$ & $R_{\mathrm{H} 2},(\%)$ & $R_{\mathrm{CH} 4},(\%)$ \\
\hline 0 & $0 / 0$ & 0 & 0 & 0 \\
\hline 90 & $100 / 0$ & 10.26 & 42.20 & 100 \\
\hline 115 & $99.09 / 0.91$ & 18.85 & 76.83 & 98.64 \\
\hline 125 & $98.33 / 1.67$ & 20.667 & 83.59 & 97.27 \\
\hline 150 & $98.27 / 1.73$ & 23.45 & 94.78 & 96.80 \\
\hline 180 & $97.22 / 2.78$ & 24.95 & 99.77 & 94.52 \\
\hline 20 & $95.34 / 4.66$ & 25.82 & 101.25 & 90.49 \\
\hline 210 & $93.66 / 6.34$ & 26.1 & 100.55 & 86.92 \\
\hline 220 & $92.02 / 7.98$ & 26.84 & 101.59 & 83.07 \\
\hline 240 & $89.65 / 10.35$ & 27.69 & 102.11 & 77.34 \\
\hline 260 & $84.28 / 15.72$ & 29.17 & 101.12 & 63.74 \\
\hline 270 & $82.22 / 17.78$ & 29.58 & 100.03 & 58.42 \\
\hline
\end{tabular}

Table 5. The results of the breakthrough experiment for the $\mathrm{CH}_{4} / \mathrm{H}_{2}(34.22 / 65.78 \mathrm{~mol} \%)$ mixture separation in a slurry of ZIF-8 $30 \mathrm{wt} \%$ + ethylene glycol $14 \mathrm{wt} \%$ + water $56 \mathrm{wt} \%$ at $273.15 \mathrm{~K}, 2.0 \mathrm{MPa}$, with an inlet flow rate of $46.20 \mathrm{~mL} / \mathrm{min}$.

\begin{tabular}{|c|c|c|c|c|}
\hline Time (min) & $y_{\text {out-H2}} / y_{\text {out }-\mathrm{CH} 4},(\mathrm{~mol} \%)$ & $v_{\text {out }},\left(\mathrm{mL} \cdot \min ^{-1}\right)$ & $R_{\mathrm{H} 2},(\%)$ & $R_{\mathrm{CH} 4},(\%)$ \\
\hline 0 & $0 / 0$ & 0 & 0 & 0 \\
\hline 50 & $100 / 0$ & 15.27 & 50.24 & 100 \\
\hline 60 & $98.90 / 1.10$ & 20.36 & 66.26 & 98.58 \\
\hline 70 & $97.70 / 2.30$ & 24.39 & 78.41 & 96.45 \\
\hline 90 & $96.46 / 3.54$ & 30.98 & 98.33 & 93.06 \\
\hline 100 & $96.25 / 3.75$ & 33.2 & 105.15 & 92.13 \\
\hline 110 & $95.44 / 4.56$ & 35.2 & 110.54 & 89.85 \\
\hline 120 & $93.93 / 6.07$ & 36.09 & 111.55 & 86.14 \\
\hline 130 & $92.25 / 7.75$ & 36.72 & 111.46 & 82.00 \\
\hline 140 & $89.56 / 10.44$ & 37.43 & 110.31 & 75.28 \\
\hline 150 & $87.15 / 12.85$ & 37.66 & 108.00 & 69.39 \\
\hline 160 & $84.16 / 15.84$ & 38.11 & 105.54 & 61.82 \\
\hline 170 & $81.12 / 18.88$ & 38.57 & 102.95 & 53.94 \\
\hline
\end{tabular}

The breakthrough times of $\mathrm{CH}_{4}$ and $\mathrm{H}_{2}$ and their differences under the different experimental conditions were summarized in Table 2. In each experiment, it was $\mathrm{H}_{2}$ that goes through the slurry bed first, and after a while $\mathrm{CH}_{4}$ can be detected, meaning that during the period before $\mathrm{CH}_{4}$ starts to break through, the collected gas is pure $\mathrm{H}_{2}$. In the circulation process, if the slurry is completely desorbed and the (ab-ad)sorption column is high enough, theoretically, pure hydrogen can be continuously obtained at the top of the 
separation column, which is an advantage of the slurry method for recovering $\mathrm{H}_{2}$ from COG. Another noticeable fact is that a low temperature, low inlet flow rate, high pressure, and high solid content are all conducive to separation and can increase the breakthrough time interval of $\mathrm{H}_{2}$ and $\mathrm{CH}_{4}$. Once a certain condition is varied, both the breakthrough times of $\mathrm{H}_{2}$ and $\mathrm{CH}_{4}$ are increased and the latter is increased by a larger margin, leading to their first breakthrough moments getting farther apart. This phenomenon indicates the higher sensitivity of $\mathrm{CH}_{4}$ to the operating conditions, so in the practical application it is easier to obtain pure $\mathrm{H}_{2}$ product in a long time by controlling the operating conditions.

\section{Conclusions}

In this work, an $\mathrm{H}_{2}$ purification process of COG that was based on the absorptionadsorption method of a ZIF-8 slurry is proposed and studied systematically by experiments. A bubble column dynamic evaluation device was used to study the (ab-ad)sorption capacity of a ZIF-8 slurry for a $\mathrm{CH}_{4} / \mathrm{H}_{2}$ mixture. The results of the breakthrough experiments in the bubble column show that a low temperature and feed flow rate, and a high operating pressure and solid content can extend the breakthrough time of $\mathrm{CH}_{4}$ and $\mathrm{H}_{2}$, as well as their interval, which is conducive to the separation of $\mathrm{CH}_{4} / \mathrm{H}_{2}$ mixture. Due to the difference of breakthrough time between $\mathrm{CH}_{4}$ and $\mathrm{H}_{2}$, pure $\mathrm{H}_{2}$ product can be obtained in a relatively long period of time by controlling the operating conditions. The breakthrough kinetics that were studied in this work provides a theoretical basis for the industrialization of the slurry process to purify $\mathrm{H}_{2}$ from $\mathrm{COG}$.

The slurry method to treat COG can be achieved by the (ab-ad)sorption-desorption column separation process. Considering how uncomplicated the process is and the available high purity of the products, the ZIF-8 slurry method is expected to have broad application prospects for $\mathrm{H}_{2}$ recovery from COG.

Author Contributions: Conceptualization, B.L. and G.C.; Data curation, X.P.; Formal analysis, W.C., M.W. and S.Y.; Funding acquisition, B.L.; Investigation, W.C., M.W., S.Y., Z.H. and M.Y.; Methodology, B.L. and G.C.; Project administration, B.L. and G.C.; Supervision, G.C.; Writing-original draft, W.C. and M.W.; Writing-review \& editing, B.L. All authors have read and agreed to the published version of the manuscript.

Funding: This research was funded by the National Natural Science Foundation of China grant number (22178378, U20B6005).

Acknowledgments: Financial support that was received from the National Natural Science Foundation of China (22178378, U20B6005) is gratefully acknowledged.

Conflicts of Interest: The authors declare no conflict of interest.

\section{References}

1. Razzaq, R.; Li, C.; Zhang, S. Coke oven gas: Availability, properties, purification, and utilization in China. Fuel 2013, 113, 287-299. [CrossRef]

2. Yang, Q.; Zhang, C.; Zhang, D.; Zhou, H. Development of a Coke Oven Gas Assisted Coal to Ethylene Glycol Process for High Techno-Economic Performance and Low Emission. Ind. Eng. Chem. Res. 2018, 57, 7600-7612. [CrossRef]

3. Bermúdez, J.M.; Fidalgo, B.; Arenillas, A.; Menéndez, J.A. Dry reforming of coke oven gases over activated carbon to produce syngas for methanol synthesis. Fuel 2010, 89, 2897-2902. [CrossRef]

4. Li, X.; Li, J.; Yang, B.; Zhang, Y. Dynamic analysis on methanation reactor using a double-input-multi-output linearized model. Chin. J. Chem. Eng. 2015, 23, 389-397. [CrossRef]

5. Taiyan, W. Problem and way of coke oven gas development and utilization. Fuel Chem. Processes 2004, 35, 1-3.

6. $\mathrm{Wu}, \mathrm{S}$.; $\mathrm{Xu}, \mathrm{X}$.; Li, X.; Bi, L. High-performance proton-conducting solid oxide fuel cells using the first-generation Sr-doped $\mathrm{LaMnO}_{3}$ cathode tailored with Zn ions. Sci. China Mater. 2021, 65, 675-682. [CrossRef]

7. Tao, Z.; Fu, M.; Liu, Y.; Gao, Y.; Tong, H.; Hu, W.; Lei, L.; Bi, L. High-performing proton-conducting solid oxide fuel cells with triple-conducting cathode of $\mathrm{Pr}_{0.5} \mathrm{Ba}_{0.5}\left(\mathrm{Co}_{0.7} \mathrm{Fe}_{0.3}\right) \mathrm{O}_{3-\delta}$ tailored with W. Int. J. Hydrog. Energy 2022, 47, 1947-1953. [CrossRef]

8. $\mathrm{Xu}, \mathrm{J}$.; Lin, $\mathrm{W}$; $\mathrm{Xu}, \mathrm{S}$. Hydrogen and LNG production from coke oven gas with multi-stage helium expansion refrigeration. Int. J. Hydrog. Energy 2018, 43, 12680-12687. [CrossRef] 
9. Van Acht, S.C.J.; Laycock, C.; Carr, S.J.W.; Maddy, J.; Guwy, A.J.; Lloyd, G.; Raymakers, L.F.J.M. Simulation of integrated novel PSA/EHP/C process for high-pressure hydrogen recovery from Coke Oven Gas. Int. J. Hydrog. Energy 2020, 45, 15196-15212. [CrossRef]

10. Huang, K.; Yuan, J.; Shen, G.; Liu, G.; Jin, W. Graphene oxide membranes supported on the ceramic hollow fibre for efficient $\mathrm{H}_{2}$ recovery. Chin. J. Chem. Eng. 2017, 25, 752-759. [CrossRef]

11. Li, L.; Qi, H. Gas separation using sol-gel derived microporous zirconia membranes with high hydrothermal stability. Chin. J. Chem. Eng. 2015, 23, 1300-1306. [CrossRef]

12. Sun, Q.; Dong, J.; Guo, X.; Liu, A.; Zhang, J. Recovery of Hydrogen from Coke-Oven Gas by Forming Hydrate. Ind. Eng. Chem. Res. 2012, 51, 6205-6211. [CrossRef]

13. Liu, H.; Wang, J.; Chen, G.; Liu, B.; Dandekar, A.; Wang, B.; Zhang, X.; Sun, C.; Ma, Q. High-efficiency separation of a CO $2 / \mathrm{H}_{2}$ mixture via hydrate formation in $\mathrm{W} / \mathrm{O}$ emulsions in the presence of cyclopentane and TBAB. Int. J. Hydrog. Energy 2014, 39, 7910-7918. [CrossRef]

14. Bermúdez, J.M.; Arenillas, A.; Luque, R.; Menéndez, J.A. An overview of novel technologies to valorise coke oven gas surplus. Fuel Process. Technol. 2013, 110, 150-159. [CrossRef]

15. Adhikari, S.; Fernando, S. Hydrogen Membrane Separation Techniques. Ind. Eng. Chem. Res. 2006, 45, 875-881. [CrossRef]

16. Sun, C.-Y.; Chen, G.-J.; Zhang, L.-W. Hydrate phase equilibrium and structure for (methane + ethane + tetrahydrofuran + water) system. J. Chem. Thermodyn. 2010, 42, 1173-1179. [CrossRef]

17. Park, K.S.; Ni, Z.; Cote, A.P.; Choi, J.Y.; Huang, R.; Uribe-Romo, F.J.; Chae, H.K.; O'Keeffe, M.; Yaghi, O.M. Exceptional chemical and thermal stability of zeolitic imidazolate frameworks. Proc. Natl. Acad. Sci. USA 2006, 103, 10186-10191. [CrossRef]

18. Song, Q.; Nataraj, S.K.; Roussenova, M.V.; Tan, J.C.; Hughes, D.J.; Li, W.; Bourgoin, P.; Alam, M.A.; Cheetham, A.K.; Al-Muhtaseb, S.A.; et al. Zeolitic imidazolate framework (ZIF-8) based polymer nanocomposite membranes for gas separation. Energy Environ. Sci. 2012, 5, 8359-8369. [CrossRef]

19. Bux, H.; Liang, F.; Li, Y.; Cravillon, J.; Wiebcke, M.; Caro, J. Zeolitic imidazolate framework membrane with molecular sieving properties by microwave-assisted solvothermal synthesis. J. Am. Chem. Soc. 2009, 131, 16000-16001. [CrossRef]

20. McCarthy, M.C.; Varela-Guerrero, V.; Barnett, G.V.; Jeong, H.K. Synthesis of zeolitic imidazolate framework films and membranes with controlled microstructures. Langmuir 2010, 26, 14636-14641. [CrossRef]

21. Liu, H.; Pan, Y.; Liu, B.; Sun, C.; Guo, P.; Gao, X.; Yang, L.; Ma, Q.; Chen, G. Tunable integration of absorption-membraneadsorption for efficiently separating low boiling gas mixtures near normal temperature. Sci. Rep. 2016, 6, 21114. [CrossRef] [PubMed]

22. Liu, H.; Liu, B.; Lin, L.C.; Chen, G.; Wu, Y.; Wang, J.; Gao, X.; Lv, Y.; Pan, Y.; Zhang, X.; et al. A hybrid absorption-adsorption method to efficiently capture carbon. Nat. Commun. 2014, 5, 5147. [CrossRef] [PubMed]

23. Li, H.; Chen, W.; Liu, B.; Jia, C.; Qiao, Z.; Sun, C.; Yang, L.; Ma, Q.; Chen, G. $\mathrm{CO}_{2}$ capture using ZIF-8/water-glycol-2methylimidazole slurry with high capacity and low desorption heat. Chem. Eng. Sci. 2018, 182, 189-199. [CrossRef]

24. Chen, W.; Zou, E.; Zuo, J.Y.; Chen, M.; Yang, M.; Li, H.; Jia, C.; Liu, B.; Sun, C.; Deng, C.; et al. Separation of Ethane from Natural Gas Using Porous ZIF-8/Water-Glycol Slurry. Ind. Eng. Chem. Res. 2019, 58, 9997-10006. [CrossRef]

25. Yang, M.-K.; Han, Y.; Zou, E.; Chen, W.; Peng, X.; Dong, B.; Sun, C.; Liu, B.; Chen, G. Separation of IGCC syngas by using ZIF-8/dimethylacetamide slurry with high $\mathrm{CO}_{2}$ sorption capacity and sorption speed but low sorption heat. Energy 2020, 201, 117605. [CrossRef]

26. Chen, W.; Guo, X.; Zou, E.; Luo, M.; Chen, M.; Yang, M.; Li, H.; Jia, C.; Deng, C.; Sun, C.; et al. A continuous and high-efficiency process to separate coal bed methane with porous ZIF-8 slurry: Experimental study and mathematical modelling. Green Energy Environ. 2020, 5, 347-363. [CrossRef]

27. Yan, S.; Zhu, D.; Zhang, Z.; Li, H.; Chen, G.; Liu, B. A pilot-scale experimental study on $\mathrm{CO}_{2}$ capture using Zeolitic imidazolate framework-8 slurry under normal pressure. Appl. Energy 2019, 248, 104-114. [CrossRef]

28. Li, H.; Liu, B.; Yang, M.; Zhu, D.; Huang, Z.; Chen, W.; Yang, L.; Chen, G. $\mathrm{CO}_{2}$ Separation Performance of Zeolitic Imidazolate Framework-8 Porous Slurry in a Pilot-Scale Packed Tower. Ind. Eng. Chem. Res. 2020, 59, 6154-6163. [CrossRef]

29. Li, H.; Chen, W.; Liu, B.; Yang, M.; Huang, Z.; Sun, C.; Deng, C.; Cao, D.; Chen, G. A purely green approach to low-cost mass production of zeolitic imidazolate frameworks. Green Energy Environ. 2021, in press. [CrossRef]

30. Chiau Junior, M.J.; Wang, Y.; Wu, X.; Cai, W. Computational screening of metal-organic frameworks with open copper sites for hydrogen purification. Int. J. Hydrog. Energy 2020, 45, 27320-27330. [CrossRef]

31. Pan, Y.; Chen, W.; Zhang, X.; Zhang, Z.; Tong, X.; Jia, C.; Liu, B.; Sun, C.; Yang, L.; Chen, G. Large-scale synthesis of ZIF-67 and highly efficient carbon capture using a ZIF-67/glycol-2-methylimidazole slurry. Chem. Eng. Sci. 2015, 137, 504-514. [CrossRef]

32. Chen, W.; Chen, M.; Yang, M.; Zou, E.; Li, H.; Jia, C.; Sun, C.; Ma, Q.; Chen, G.; Qin, H. A new approach to the upgrading of the traditional propylene carbonate washing process with significantly higher $\mathrm{CO}_{2}$ absorption capacity and selectivity. Appl. Energy 2019, 240, 265-275. [CrossRef]

33. Peng, X.; Jia, C.; Qiao, Z.; Yang, S.; Liu, B.; Deng, C.; Li, H.; Chen, W.; Sun, C.; Chen, G. A new energy efficient process for hydrogen purification using ZIF-8/glycol-water slurry: Experimental study and process modeling. Int. J. Hydrog. Energy 2021, 46, 32081-32098. [CrossRef] 